\section{The effect of the duration of the warning}

\section{signal on extinguishing avoidance responses in Fischer 344 rats}

\author{
RICHARD KATZEV \\ Reed College, Portland, Oreg. 97202
}

Whenever an animal fails to respond during extinction trials in a discriminative avoidance procedure, shocks are omitted and the warning signal is terminated arbitrarily after some fixed interval. This experiment examined the effects of variations in the duration of this interval on the performance of inbred rats of the Fischer ${ }_{344}$ strain during shuttlebox extinction trials. Immediately following training to a criterion level of performance, the Ss were divided into four groups on the basis of the duration (ranging from 5 to $20 \mathrm{sec}$ ) of the warning signal before its arbitrary termination. The probability of responding during such extinction trials was an increasing monotonic function of the duration of this interval.

The probability of responding during extinction trials in the discriminative avoidance procedure depends critically on the manner in which the warning signal ends. In this procedure, there are two occasions when the contingencies of warning signal termination can be manipulated. The first occurs on those trials when the warning signal ends following the occurrence of an avoidance response. It has been widely observed (e.g., Robinson, 1961; Solomon, Kamin, \& Wynne, 1953) that responding is often quite persistent as long as the signal continues to terminate immediately after such responses, even when shock is no longer programmed. In contrast, several recent reports (e.g., Katzev, 1967; Delprato, 1969) have indicated that when this contingency is changed, so that the warning signal ceases to end immediately, animals very quickly stop making avoidance responses.

There is, in this procedure, a second occasion when the termination of the warning signal can be manipulated. This occurs on trials when the animal fails to respond and the $E$ is required to end the warning signal after some arbitrary interval. The duration of this interval has varied widely in experimental studies of the extinction of avoidance responses. For example, although many investigators have employed in extinction the same interval held during the CS-US interval in acquisition, others have used considerably longer intervals, ranging from $15 \mathrm{sec}$ to $2 \mathrm{~min}$. The following experiment examines the manner in which such variations influence the likelihood of responding during extinction trials by varying the duration of the warning signal prior to its arbitrary termination on those trials when a response did not occur. In one condition the CS duration in extinction runs the same as the CS-US interval during acquisition trials. In each of the remaining groups the duration of this interval was time in which the organism could respond before the warning signal ended.

\section{SUBJECTS}

Twenty-four experimentally naive male rats of the inbred Fischer 344 strain were assigned randomly to four groups of six each. The animals were obtained from the Simonsen Laboratory, Gilroy, California, and were between 100 and 115 days old when the experiment began. The rats were housed individually and had free access to both food and water.

$$
\text { APPAR ATUS }
$$

The experimental chamber was an automated shuttlebox (manufactured by the Lafayette Instrument Company) which consisted of two stainless steel modular testing units bolted together end to end without a barrier or door. The overall dimensions of the box were $24 \mathrm{in}$. long $\times 7^{3 / 4} \mathrm{in}$. wide $\times 8$ in. high.

\section{PROCEDURE}

The CS was an increase in illumination (from 0 to $100 \mathrm{fc}$ ) from two 15-W incandescent bulbs mounted above the translucent white Plexiglas ceiling of the box. The US was shock by a Foringer shock source and scrambling unit. About $250 \mathrm{~V}$, through an in-series resistance of $250,000 \mathrm{ohms}$, was delivered to the animal through the stainless steel grid floor of the shuttlebox. The floor of each half of the box was independently hinged and was displaced vertically about $1 / 8 \mathrm{in}$. whenever an animal stepped on it. The stimuli were presented automatically, and the responses were recorded by Foringer control equipment. progressively longer, providing more
Each animal was tested in a single session consisting of training to a criterion level of performance, followed immediately by 100 extinction trials. The training criterion required 10 consecutive avoidance responses after the initial 25 acquisition trials. The intertrial interval during both acquisition and extinction ranged from 15 to $75 \mathrm{sec}$, with a mean of $35 \mathrm{sec}$.

Acquisition

Each animal was given a 2-min adaptation period prior to the start of the first trial. The CS-US interval for trials during this phase of the experiment was $5 \mathrm{sec}$. If a rat failed to respond within this interval, the shock was turned on and both the CS and US remained on until the animal crossed over into the other compartment, whereupon both were promptly terminated. In contrast, whenever the rat did respond within this interval, the CS terminated immediately and shock was not delivered.

\section{Extinction}

Following Katzev (1967), an extinction trial was defined as one in which neither shock nor prompt CS termination occurred. Accordingly, whenever an animal responded on such trials, the termination of the warning signal was delayed for 2 sec. Each response made during this delay period reset the timer controlling the delay so that the CS did not terminate until the animal had failed to make a crossing for $2 \mathrm{sec}$. On the other hand, whenever the animal did not respond after the start of the trial, the CS was arbitrarily terminated. The length of this interval varied between the groups. Four intervals were employed: $5,7.5,10$ and 20 sec. Thus, each experimental condition was distinguished on the basis of the length of the trial before the CS was arbitrarily terminated. Although the latencies of all responses less than each such interval were

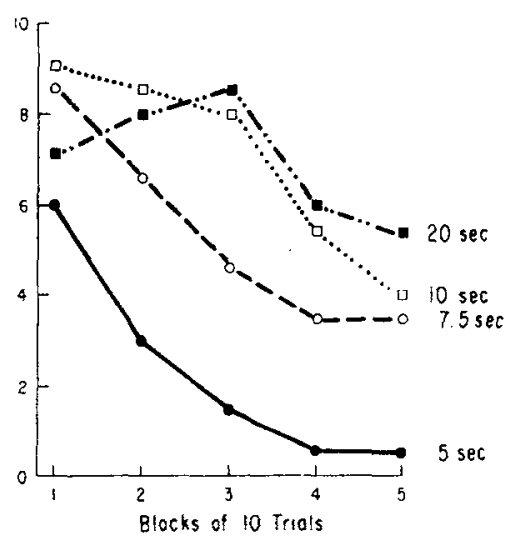

Fig. 1. Median number of avoidance responses for each condition during each block of 10 trials during the first 50 extinction trials. 


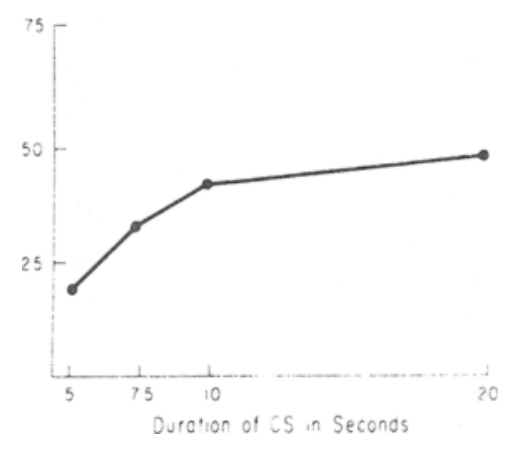

Fig. 2. Median number of avoidance responses during 100 extinction trials as a function of the duration of the warning signal.

recorded, only those which occurred in less than $5 \mathrm{sec}$ were counted as avoidance responses (CRs). Shock was never delivered on extinction trials.

\section{RESULTS}

As we have reported previously (Katzev \& Henderson, 1971), rats of the Fischer 344 strain learn rapidly to perform avoidance responses. In the present study, most of the animals met the acquisition criterion by Trial 35, though many of them had been avoiding each scheduled shock for more than the last 10 training trials. There were no differences between the treatment conditions in terms of the mean number of trials to reach the acquisition criterion (Kruskal-Wallis analysis of variance by ranks, $\mathrm{H}=.33$; $\mathrm{df}=3 ; \mathrm{p}>.95)$.

Figure 1 shows the median number of avoidance responses made by each group during the first 50 extinction trials. Animals exposed to the 5-sec condition stopped making avoidance responses quickly so that they had virtually ceased responding by the end of the first half of the extinction session. This contrasts with the progressively greater likelihood of responding in the remaining conditions. As the duration of the warning before its arbitrary termination is increased, the animals are more and more likely to continue making avoidance responses.

Figure 2 plots the median number of avoidance responses for the entire extinction period made under each of these treatment conditions. Animals in the 5-sec duration condition made CRs on about $20 \%$ of the trials, with most of these occurring relatively early in the session. On the other hand, animals in the 7.5-, 10-, and 20 -sec-duration conditions were more and more likely to respond throughout the session, with this increasing likelihood a direct function of the interval's duration. Ferguson's (1966) nonparametric trend test was employed to test for the presence of a trend in the total number of avoidance responses during extinction trials. This test revealed that avoidance responding during such trials was a significant monotonic increasing function of the length of the interval before the trials was terminated $(\mathrm{z}=3.05, \mathrm{p}<.001)$.

Figure 3 shows the median number of trials on which the CS actually terminated before a response during the entire extinction period for each of the treatment conditions. This measure specifies exactly the occurrence of the treatment variable under consideration and is based on the number of trials each animal failed to respond within $5 \mathrm{sec}$ or before the trial could be arbitrarily terminated at the end of the fixed interval. It is clear from Fig. 3 that, as the duration of this interval increases, animals are less and less likely to receive a trial in which the CS ends before a response. Ferguson's nonparametric trend test reveals that the occurrence of trials in which the CS terminates before a response is a significant monotonic decreasing function of the duration of this interval $(\mathrm{z}=-2.20 ; \mathrm{p}<.02)$.

\section{DISCUSSION}

In short, the level of responding during extinction trials under the discriminative avoidance procedure is a direct function of the duration of the warning signal before its arbitrary termination. When this interval is relatively short, the response weakens quickly; as it increases, there is a greater likelihood of continued avoidance responding. Moreover, under the present extinction procedure, this facilitation occurred even though each such response was not immediately reinforced with prompt signal offset.

Does the termination of the warning signal prior to the occurrence of a response weaken avoidance behavior? Although several investigators (see (Bandura, 1969, pp. 390-397) have reported that avoidance responses can be extinguished by gradually increasing the intensity of the warning signal, they have not explicitly manipulated the contingency of prior signal offset. The present experiment, however, provides direct evidence on this question; if we decrease the duration of the warning signal, the organism has less opportunity to respond. In turn, this results in an increased likelihood that he will receive a trial in which the CS can shut off before a response. As Fig. 3 indicates, the more frequently such trials are presented, the more likely animals will stop responding. Thus, conditions which increase the chances of terminating a trial before a response do appear to facilitate the weakening

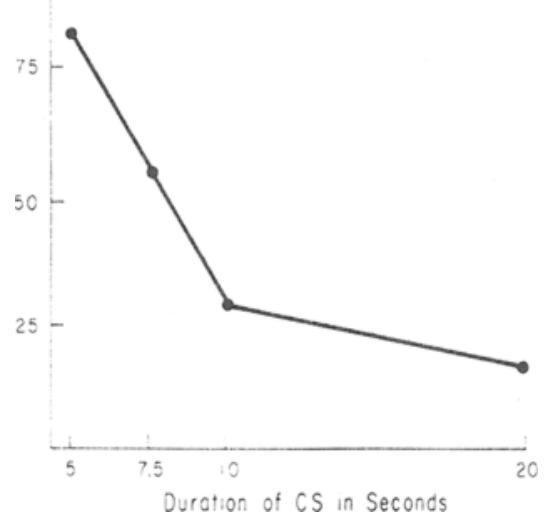

Fig. 3. Median number of trials in which the warning signal terminated before a response as a function of the duration of the warning signal.

\section{of well-established avoidance} responses.

How does this finding explain the wide variability in responding often reported between experimental studies of the extinction of avoidance responses? Although some Es report that their animals stop responding after only a few trials, others observe that their animals continue to respond for trial after trial. In order to account for such differences, it is important to note that each time the CS terminates before a response, avoidance behavior is weakened and there is an increased likelihood that another long latency response will occur when the animal can again be given that kind of trial. However, such trials can be given much more often if an $E$ uses a short interval rather than a long one. Because Es differ widely in the duration of the interval they employ, they also differ in the degree to which they can control the presentation of this kind of extinction trial. Thus, it is not surprising that some report relatively rapid extinction while others report that their animals continue to respond for extended periods.

The implications of this study for the more general question of how to reduce the likelihood of persistent avoidance responses are clear. In order to weaken such well-established responses, two requirements must be met. First, a failure to respond must not be followed by shock. Secondly, it is necessary to establish procedures in which the organism remains in the presence of the warning signal long enough to experience that contingency. Removing the several varieties of response-contingent feedback has been interpreted as one such procedure (Katzev \& Hendersen, 1971). The results of the present 
parametric study suggest another. Shortening the duration of the interval before the warning signal is arbitrarily terminated increases the likelihood that the trial will end before a response. Each time the animal receives such a trial, the response weakens. As a result, the animal should be less and less likely to respond on subsequent trials. Thus, this procedure, by increasing the occurrence of trials in which a failure to respond is no longer followed by shock, should facilitate a relatively rapid and sustained weakening of persistent avoidance responses.

\section{REFERENCES}

BANDURA, A. Principles of behavior modification. New York: Holt, Rinehart, \& Winston, 1969.

DELPRATO, D. Extinction of one-way avoidance and delayed warning signal termination. Journal of Experimental Psychology, 1969, 80, 192-193.

FERGUSON, G. Statistical analysis in psychology and education. New York: McGraw-Hill, 1966.

KATZEV, R. Extinguishing avoldance response as a function of delayed warning signal termination. Journal of
Experimental Psychology, 1967, 75 , 339-344.

KATZEV $R$ \& HENDERSON, R Effects of exteroceptive feedback stimuli on extinguishing avoidance response in Fischer 344 rats. Journal of Comparative \& Physiofogical Psychology, 1971, 74, 66-74.

ROBINSON, H. Persistence of a response in the apparent absence of motivation. Joumal of Experimental Psychology. $1961,61,480-488$.

SOLOMON, R., KAMIN, L., \& WYNNE, L. Traumatic avoidance learning: The outcomes of several extinction procedures with dogs. Journal of Abnormal \& Social Psychology, 1953, 48, 291-302.

\section{CURRENT LITERATURE ON AVOIDANCE \& PUNISHMENT IN ANIMALS}

DARDANO, J. F. (Division of Behavioral Biology, Johns Hopkins University School of Medicine, Baltimore, Md. 21205). Control of concurrent avoidance and appetitive behaviors by an indicator of shock proximity. Journal of the Experimental Analysis of Behavior, $1971,15,167-180$.

FINDLEY, J. D. (Johns Hopkins University School of Medicine, Baltimore, Md. 21205), Robison, W. W., \& GILLIAM, W. A restraint system for chronic study of the baboon. Journal of the Experimental Analysis of Behavior, 1971, 15, 69-71.

HUTCHINSON, R. R. (Western Michigan University, Kalamazoo, Mich. 49001), RENFREW, J. W., \& YOUNG, G. A. Effects of long-term shock and associated stimuli on aggressive and manual responses. Journal of the Experimental Analysis of Behavior, 1971, 15, 141-166.

KRASNEGOR, N. A. (Department of Experimental Psychology, Division of Neuropsychiatry, Walter Reed Army Institute of Research, Walter Reed Army Medical Center, Washington, D.C. 20012), BRADY, J. V., \& FINDLEY, J. D.
Second-order optional avoidance as a function of fixed-ratio requirements. Journal of the Experimental Analysis of Behavior, $1971,15,181-187$

RESCORLA, R. A. (Yale University, New Haven, Conn. 06510). Summation and retardation tests of latent inhibition. Journal of Comparative and Physiological Psychology, 1971, 75, 77-81.

ROHRBAUGH, M., BRENNAN, J. F., \& RICCIO, D. C. (Kent State University, Kent, Ohio 44240). Control of two-way shuttle avoidance in rats by auditory frequency and intensity. Journal of Comparative and Physiological Psychology, 1971, 75, 324-330.

PARE, W. P. (Pavlovian Research L a b o r a t ory, Veterans Administration Hospital, Perry Point, Md. 21902). Six-hour escape-avoidance work shift and production of stomach ulcers. Journal of Comparative and Physiological Psychology, 1971, 74, 459-466.

POWELL, R. W. (Department of Behavioral Science, University of South Florida, Tampa, Fla. 33620). Free-operant (Sidman) avoidance in field-raised and laboratory-raised wild rats. Journal of Comparative and Physiological Psychology, 1971, $75,216-225$.

ROBERTS, C. L. (Colorado College, Colorodo Springs, Colo. 80903), \& BLASE, $K$. Elicitation and punishment of intraspecies aggression by the same stimulus. Journal of the Experimental Analysis of Behavior, 1971, 15, 193-196.

WEISMAN, R. G. (Queen's University, Kingston, Ontario, Canada), \& LITNER, J. S. Role of the intertrial interval in Pavlovian differential conditioning of fear in rats. Journal of Comparative and Physiological Psychology, 1971, 74, 211-218.

WONG, P. T. P. (University of Texas, Austin, Tex. 78712). Coerced approach to shock and resistance to punishment suppression and extinction in the rat. Joumal of Comparative and Physiological Psychology, 1971, 75, 82-91.

WOODARD, W. T. (University of South Florida, Tampa, Fla. 33620), \& BITTERMAN, M. E. Punishment in the goldfish as a function of electrode orientation. Behavior Research Methods \& Instrumentation, 1971, 3, 72-73. 